\title{
ENT diseases presenting to a tertiary care hospital
}

\author{
Abstract \\ Objectives: To determine the frequency of different ENT diseases presenting at \\ outpatient department and to educate people about different ENT diseases, their early \\ treatment and prevention.
}

Methodology: An observational cross sectional study was performed in Ayub Teaching Hospital, Abbottabad between 15 May 2016 and 10 Aug 2016. A non-probability convenient sampling technique was used to collect data from 250 participants from patients presenting at OPD. Data about patient particulars and different diseases was collected through a well-structured questionnaire. Data was secured and confidentiality was maintained. Data was analyzed using SPSS 21.

Results: Out of all participants 250, 129(51.6\%) were males and 121(48.4\%) were females. Most of them $76(30.3 \%)$ had only primary education and a good number were also matriculate. Majority of the patient $165(66 \%)$ were socio-economically poor. Ear problems were most commonly encountered. Among ear problems, bilateral ear wax was the most common $38(15.2 \%)$ followed by acute otitis media $33(13.2 \%)$ and chronic suppurative otitis media $27(10.8 \%)$. Throat problems were $2^{\text {nd }}$ in number to the ear problems. Most commonly presented throat problems were of tonsillitis including both acute and chronic conditions accounting for 39(15.6\%) cases. Nose problems comes behind the ear and throat diseases and most common problems were of allergic rhinitis $33(13.2 \%)$ and DNS $20(8 \%)$. Cases of sinusitis and epistaxis had a very low frequency. Most of these patients were suffering from these problems for the last one year. Most of them had taken medical treatment from the Govt. Hospitals.

Conclusion: Among ENT diseases, ear diseases are most common followed next by nose and then throat diseases. Most of these diseases are of acute onset with less than a year of disease duration. They exist mainly in low socio-economic class and most of the patient avail the medical treatment.

Keywords: ENT diseases, OPD, frequency, otitis media, medical treatment
Special Issue - 2018

\author{
Muhammad Zeeshan,' Junaid Zeb, ${ }^{2}$ Maaz \\ Saleem,' Amjad Zaman S,' Asif Khan,' \\ Muhammad Tahir' \\ 'Department of Surgery, House Officers Ayub Teaching Hospital, \\ Pakistan \\ ${ }^{2}$ Department of Anatomy, Khyber medical college, Pakistan
}

Correspondence: Junaid Zeb, Department of Anatomy, Khyber medical college, Peshawar, Pakistan, Tel+ 0342-9070725, Email junaidzeb100@gmail.com

Received: December 19, 2017 | Published: November 15, 2018

\section{Introduction}

The usual problems which makes a patient to visit doctor or health care provider in both rural as well as urban communities are related to the ENT. ${ }^{1,2}$ Many developing countries have few experts and very poor facilities to support the experts and thus creates a very heavy workload on otorhinolaryngologists. ${ }^{3}$ There are a lot of ENT diseases which range from minor problems like allergies to severe problems like malignancies which affect lives of people and is becoming a public health problem. Some ENT diseases are congenital and others are acquired. The acquired causes may be trauma, infections, inflammation, vascular and neurological. Some are of acute while others are of chronic onset. ${ }^{4}$ According to World Health Organization 42 million people (age $>3$ years) have hearing loss. The prevalent cause is otitis media, in childhood infection common cold is the first main cause. ${ }^{5}$ Firstly, and the Eustachian tubes are very smaller and straight in children as compared to adults. Moreover, children defense mechanism is underdeveloped as compared to adults. ${ }^{6,7}$ and mostly not diagnosed earlier and treated poorly in initial phase, it can go to chronic phase which is the chronic supportive otitis media. This chronic condition can lead to many complications even in death. Each year around 2100 people die due to complications of otitis media. ${ }^{8}$ Rupture of the tympanic membrane which is very common, can be caused either by acute or chronic middle ear infections or by trauma. It may lead to conductive hearing loss otitis media. ${ }^{9}$ DNS is malalignment of nasal septum which may be either congenital or caused by trauma. Epitasis is another condition in which bleeding occurs from the nose. Most common cause is finger nail trauma. Other include high $\mathrm{BP}$, use of anticoagulants, infection, liver disease etc. ${ }^{10} \mathrm{ENT}$ diseases are responsible for considerable morbidity among infants and young children. Acute infections of upper respiratory as well as recurrent disease and disorder of Ear, Nose and Throat are more common in early stages of life. If remain untreated it may complicate and endanger the life of an induadual and may affect the developmental capability of the child. ${ }^{11}$ Otitis media is the most common disorder in infants and children and is common cause of deafness in child. A study was conducted on ENT disorders in children in India, it was found that otitis media is the most common in male children (53.2\%). Most of these children were from lower socioeconomic families, children living in combine families and had uneducated mothers. ${ }^{12}$ A similar study was conducted on children in UAE and the results were that otitis media was second most common disease after rinitis. ${ }^{13}$ A study was also conducted on complications of otitis media and it was found that perforations in the tympanic membrane was the most common complication of otitis media followed by cholesteotoma, mastoidits wand atelectasis of tympanic membrane. ${ }^{14}$

A study was conducted on causes of perforation of tympanic membrane showed that it is caused by either acute or chronic infection or by trauma. It causes conductive hearing loss and predisposes ear to infection. Some perforations heals spontaneously and other by surgery. ${ }^{15}$ A study was conducted in which group A 
beta hemolytic streptococcus was isolated by pharyngeal culture in 2 years old children. Patient's who's age were less than 2 years had a greater frequency of fever, skin eruption and catarrhal (influenza like) symptoms than older children. The results of the study were pharyngeal irritation $90.7 \%$, odynophagia and adenopathies in $55.8 \%$. The two peaks occur in May and September and sporadic cases occur throughout the year. ${ }^{16}$ Laryngeal cancer is common cancers of the throat. According to research of National Cancer Registry, ICMR, 2005 report, laryngeal cancer occurs at 3.29 new cases in male and 0.42 new cases in female per 100,000 populations. Another study was conducted on black South Africans for the risk factors of laryngeal cancer and it was found that smoking and alcohol were the major causes of laryngeal cancers. ${ }^{17}$ This study was designed to determine the frequency of common ENT diseases presenting at ENT OPD and to educate about these diseases, early treatment and prevention.

\section{Materials and methods}

It was a Descriptive cross sectional study done at Ayub teaching hospital in ENT department to find the frequency of ENT diseases. It lasts from May 15 to August 10, 2016. Our study population was all patients of ENT OPD at Ayub Teaching Hospital, Abbottabad (ATH, Atd). Data was collected and entered using "Sample size determination in health studies". Sample consists of 250 patients who were selected using categorical sampling.

Inclusion criteria: Patients having ENT diseases.

Exclusion criteria: patients having diseases other than ENT problems and admitted patient.

Data was collected by using non probable convenient sampling. A pre-tested questionnaire consisting of questions about frequency of diseases related to ENT and questions about diagnosis and duration were commonly used in surveys. Data was obtained by filling questionnaires. Data was secured and confidentiality was maintained. The data was entered and analyzed using computer software SPSS version 21. The quantitative variables like Age, monthly income and duration of disease were described as mean \pm standard deviation. Categorical variables lie gender, education, occupation, socioeconomic status, treatment taken before and current diagnosis were described in terms of frequencies and proportion. Data was presented in the tables and figures.

\section{Results}

We studied a total sample of 250 patients (mean age $=27.63$ years with minimum of 1 and maximum of 77). Majority of patients 181(72.4\%) presenting to ENT OPD belongs to district Abbott bad, small number of patients from neighboring districts like Mansehra $27(10.8 \%)$ and $13(5.2 \%)$ from Haripur. In addition, 29(11.6\%) patients were from other districts. Among total of 250 of our study participants, $129(51.6 \%)$ were male and 121(48.4\%) were females. The socioeconomic status of population showed that majority of them $165(66 \%)$ belong to poor class, $72(28.8 \%)$ belong to middle class while only small number of patients $13(5.2 \%)$ belong to the upper class. Employment status was such that majority of the patients $54(21.6 \%)$ were govt. servant while $28(11.2 \%)$ were laborers. Most of the patients $77(30.8 \%)$ were related to the other occupations including private jobs. Those who do not work also contribute a quite good number 44(17.6\%). Most of the patient having ENTdiseases belongs to the urban life $172(68.8 \%)$ while a small number of patients were from Rural areas 78(31.2\%). The large number of patients from urban population is due to easy access of the patients as compared with rural areas. Most of the patients $127(50.8 \%)$ presenting to ENT OPD were unmarried while $119(47.6 \%)$ were married. $3(1.2 \%)$ were divorced and only one patient (.4\%) was widow. This table shows that ear wax is the most common condition which causes a large number of patients $38(15.2 \%)$ to attend the ENT OPD. The common diseases lying next to the ear wax are acute otitis media and allergic rhinitis $33(13.2 \%), 33(13.2 \%)$ patients respectively. Chronic supportive otitis media (CSOM) lies next in the list. Chronic tonsillitis 26(10.4\%) and acute pharyngitis $2(8.4 \%)$ has also a quite good number of patients. Many patients also had Deviated nasal septum (DNS) 20(8.0\%). This table also shows that epitasis, otitis external and acute sinusitis although present but there prevalence is low as compared to other conditions discussed above. According to the duration of illness, most of the patient $193(77.2 \%)$ were suffering from the condition from less than 1 year of duration. $46(18.4 \%)$ of the patients were having the duration of the disease ranging from the $1-5$ year while only $4(1.6 \%)$ patients were having the disease for greater than 10 years. Majority of the patients $119(47.6 \%)$ are taking treatment from Gov. While a few number $29(11.6 \%)$ from private hospital. $9(37.2 \%)$ patients were not taking any treatment at all. Nature of the visit of patient, either first time or follow up. It shows that most of patient 133(53.2\%) attending the ENT OPD were came for follow up and $117(46.8 \%)$ were came for first visit.

\section{Discussion}

The frequency of ear, nose, and throat disorders among children as well as adults is increasing health problem in Pakistan. This study aims to determine incidence of ENT diseases in patients attending the ENT OPD. Firstly, ear wax is the most prevalent ENT disease followed by acute otitis media (AOM) \& chronic supportive otitis media (CSOM), secondly earwax effect $6 \%$ of the general population and is considered major health problem world wide. ${ }^{18-20}$ Our study also revealed high prevalence rate of earwax in both children as well as adults. Okafor found in southern part of Nigeria that wax is the third common cause of hearing disease..$^{21}$ Sanjay $\mathrm{p}$ et al. ${ }^{22}$ conducted study and showed presence of acute otitis media (AOM) in majority followed by CSOM.22 chronic supportive otitis media and its association with deafness continues to be a common health problem in socioeconomic settings. Providing improved health services and good access to health care among children in such communities is necessary to decrease the burden of illness. ${ }^{23}$ Allergic rhinitis is one of the common ENT disorder presented in ENT OPD in our study population. Additionally, allergic rhinitis significantly impairs quality of life; congestion causes allergic rhinitis sufferers decreased daytime productivity at work or school and reduces night-time sleep time and quality. Annually, allergic rhinitis leads to approximately $\$ 6$ billion in overall health care expenditures and affects tenth of millions of Americans. These result are in accordance with our study. ${ }^{24}$ Deviated nasal septum (DNS) is quite common, being present in approximately $20 \%$ of all newborns. External injury is also one of its cause.$^{25}$ This high prevalence rate of DNS is in accordance with our study. According to our study, epistaxis in children is seen only in small number of cases. This result is similar to a Nigerian study. ${ }^{26}$ It is commonly presented in $3^{\text {rd }}$ decade of life and the fact that the peak incidence was between 21-30 years could also be responsible for trauma being the most common cause since people in the age group is often agile and also involved in sporting activities. Pharyngitis is one of the most frequent illnesses seen in a study ${ }^{27}$ But in current studies it constitutes only $12.4 \%$. 
Chronic tonsillitis is another common problem seen at an Otorhinolaryngology clinic. Recurrent tonsillitis can be a source of upper \& lower respiratory infections. Enlargement can lead to sleep problem breathing, eating disorders \&even growth problems. ${ }^{28,29}$ The current study shows incidence of tonsillitis is $15.6 \%$ which is less comparable to study by Sanjay et al. ${ }^{22}$ which showed $42.9 \%$ of cases. The strength of the study was the high response rate; however, this study was carried out only in one Government Hospital. The gender ratio of our study participants is almost same with only a very small difference. Approval from Ethics committee was taken. Some respondents left some panels blank. Patient's confidentiality about their privacy was gained in data collection. Another limitation of our study was that we focused mainly on the major ENT diseases presented in ENT OPD and their prevalence not taking into consideration their causes and treatment.

\section{Conclusion}

From the current study, it is concluded that among ENT disorders presenting to ENT OPD, majority of them in this region are ear problems followed next by nose and then throat diseases. Most of these diseases are of acute onset with less than a year of disease duration. ENT diseases are common in people with low education level. They exist mainly in low socio-economic class and most of the patient avail the medical treatment. A good point is that most of the people do follow up.

\section{Acknowledgements}

None.

\section{Conflict of interest}

The author declares no conflict of interest.

\section{References}

1. Eziyi JAE, Amusa YB, Akinpelu OV. Prevalence of Otolaryngological diseases in Nigerians. East Central Afr J Surg. 2010;15(2):85-89.

2. Khan AR, Arif S. Ear nose and throat injuries in children. $J$ Ayub Med Coll Abbottabad. 2005;17(1):54-56.

3. Biswas AC, Joarder A H, Siddiquee BH. Prevalence of CSOM among rural school going children. Mymensingh Med J. 2005;14(2):152-155.

4. Otorhinolaryngology. 2016.

5. World Health Organization. 2016.

6. Khan AR, Khan SA, Arif AU, et al. Analysis of ENT diseases at Khyber teaching hospital, Peshawar. J Med Sci. 2013;21(1):7-9.

7. Maharajan M. Prevalence of otitis media in school going children in eastern Nepal. Kathmandu Uni Med J. 2006;16(4):479-482.

8. OConnor TE, Perry CF, Lannigan FJ. Complications of otitis media in Indigenous and non-Indigenous children. Med J Aust. 2009;191(9):60-64.

9. Dhingra PL, Dhingra S. Diseases of EAR, NOSE and Throat and Head and Neck Surgery. 6th ed. India: Elsevier; 2014.
10. Warall G. Acute sinusitis. Can Farm Physicain. 2011;57(5):565-567.

11. Hamid A, Sattar F, Din SE. Prevalence rate and morbidity pattern of common ENT diseases and disorders in infants and children. J Postgrad Med Inst. 1991;5(2):59-67.

12. Kishve SP, Kumar N, Kishve PS, et al. Ear, Nose and Throat disorders in pediatric patients at a rural hospital in India. Australasian Med $J$. 2010;3(12):786-790.

13. Yeli SS. Prevalence of ENT disorders among children in UAE. A tertiary medical care study. Int J Curr Microbiol App Sci. 2015;4(7):682-687.

14. Farrior J. Complications of otitis media in children. South Med J. 1990;83(6):645-648.

15. Sarojamma k, Raj S, Satish SH. A Clinical Study of Traumatic Perforation of Tympanic Membrane. IOSR J Dent Med Sci. 2014;13(4):24-28.

16. Stelter K. Tonsillitis and sore throat in children. GMS Curr Top Otorhinolaryngol Head Neck Surg. 2014;13(12):115-123.

17. Norman RP, Urban MI, Sitas F, et al. Risk factors for esophageal, lung, oral and laryngeal cancers in black South Africans. Br J Cancer. 2002;86(11):1751-1756.

18. Adegbiji WA, Alabi BS, Olajuyin OA, et al. Earwax Impaction: Symptoms, Predisposing Factors and Perception among Nigerians. J Family Med Prim Care. 2014;3(4):379-382.

19. Stransky K, Valterova I, Kofronova E, et al. Non-polar lipid components of human cerumen. Int J Lipids. 2011;46(8):781-788.

20. Mitka M. Cerumen removal guidelines wax practical. JAMA. 2008;300(13):1506-1509.

21. Okafor BC. Otolaryngology in southeastern Nigeria, pattern of diseases of the ear. Nigeria Med J. 1983;13(1):11-19.

22. Sanjay P, Kishve N. Ear, Nose and throat disorders in pediatric patients at a rural hospital in India. Australasian Med J. 2010; 3(12):786-790.

23. Muftah A, Mackenzie I, Faragher B, et al. Prevalence of Chronic Suppurative Otitis Media (CSOM) and Associated Hearing Impairment Among School-aged Children in Yemen. Oman Med J. 2015;30(5):358-365.

24. Stewart M, Ferguson BJ, Fromer L. Epidemiology and burden of nasal congestion. Int J Gen Med. 2010;3(4):37-45.

25. Luers JC, Welzing L, Roth B, et al. Traumatic luxation of nose in a newborn, case report and review of literature. Eur Arch Otorhinolaryngol. 2009;266(9):1489-1493.

26. Eniolaa EJA, Bolaa AY, Clementx N. The prevalence of nasal diseases in Nigerian school children. J Med Sci. 2014;5(4):71-77.

27. Ebell MH, Smith MA, Barry HC, et al. The rational clinical examination. Does this patient have strep throat? JAMA. 2000;284(22):2912-2918.

28. Karo CO, Cherian T. Prevalence of tonsillar hypertrophy \& associated oropharyngeal symptoms in primary school children in Denizli, Turkey. Int J pediatr otorhinolaryngol. 2012;66(2):175-179.

29. Potsic WP, Gonzallo AK, Havas T, et al. Assessment and treatment of adenotonsillar hypertrophy in children. American $J$ otolaryngol. 2011;13(5):259-264. 